\title{
Pediatric pulmonology year in review 2016: Part 2
}

\author{
Richard Auten $^{1}$ | Clement Ren ${ }^{2}$ | Ozge Yilmaz ${ }^{3}$ | Terry L. Noah ${ }^{4}$ (iD
}

${ }^{1}$ ConeHealth_System, Greensboro, North Carolina

2 Department of Pediatrics, Riley Children's Hospital, Indiana University School of Medicine, Indianapolis, Indiana

3 Pediatric Allergy and Pulmonology, Celal Bayar University Department of Pediatrics, Manisa, Turkey

${ }^{4}$ Department of Pediatrics, University of North Carolina at Chapel Hill, Chapel Hill, North

Carolina

Correspondence

Terry L. Noah, University of North Carolina, 450 Macnider Building, Campus Box 7217, Chapel

Hill, NC 27599-7217.

Email: terry_noah@med.unc.edu

\begin{abstract}
Pediatric Pulmonology continues to publish research and clinical topics related to the entire range of children's respiratory disorders. As we have done annually in recent years, we here summarize some of the past year's publications in our major topic areas, as well as selected literature in these areas from other core journals relevant to our discipline. This review (Part 2) covers selected articles on neonatology, asthma, physiology and lung function testing, and infectious diseases.
\end{abstract}

\section{KEYWORDS}

asthma, infections, neonatal pulmonary medicine, pulmonary function testing (PFT)

\section{1 | INTRODUCTION}

Pediatric Pulmonology continues to publish research and clinical topics related to the entire range of children's respiratory disorders. As we have done annually in recent years, we here summarize some of the past year's publications in our major topic areas, as well as selected literature in these areas from other core journals relevant to our discipline. This review (Part 2) covers selected articles on neonatology, asthma, physiology and lung function testing, and infectious diseases.

\section{2 | NEONATOLOGY}

Since mechanical ventilation inevitably exposes the developing respiratory system to unpredictable mechanical strains and stresses, clinicians have long sought safer and less invasive approaches to respiratory support, and better tools with which to monitor respiratory function during intensive care. There has been a trend to substitute high flow nasal cannulae which are able to deliver positive pressure, but this pressure is typically not regulated or monitored. In an effort to define the limitations of this approach, Gerdes et al ${ }^{1}$ identified factors affecting delivered mean airway pressure during nasal CPAP delivery with the RAM $^{\mathrm{TM}}$ cannula, an increasingly widely used device favored by some because of its apparent toleration compared with other devices that require more complex fixation systems. Using a polymer model of the upper airway and lip, RAM cannulae, and corresponding standard nCPAP prongs were affixed and delivered pressures measured using a pneumotachograph. As expected, complete occlusion of the nasal passage with either the RAM cannula or "standard" nasal prongs delivered comparable pressures that approximated the set pressure, providing that the RAM cannula was fully inserted. However, the authors point out a critical limitation to using the RAM cannula, namely that nasal expiratory resistance will be quite high if the nares are occluded.

For babies that must be managed with mechanical ventilation, efforts are underway to improve both delivery and accurate monitoring of therapy. The safe use of high-frequency ventilation in newborns limits the ability of the clinician to assess ventilation in realtime. Minute ventilation and tidal volume cannot be measured, and capnography has been limited to transcutaneous $\mathrm{CO}_{2}$ measurements, which have been problematic in very premature newborns that may not tolerate the skin temperatures that until very recently have been required for accurate measurement. Kugelman et $\mathrm{al}^{2}$ evaluated capnography using a 2-lumen endotracheal tube and microstream capnography correlated with arterial blood gas measurements obtained from an indwelling line. Although accuracy was not acceptable, capnography was able to predict very low $\mathrm{P}_{\mathrm{a}} \mathrm{CO}_{2}<30$ Torr and very high $\mathrm{P}_{\mathrm{a}} \mathrm{CO}_{2}$ above 60 Torr.

Respiratory volumes can also be assessed non-invasively using electrical impedance. Van der Burg et $\mathrm{al}^{3}$ were able to demonstrate that alterations of positioning had little discernable effect on apparent tidal volume, oxygen saturation, or respiratory rate. Since there is controversy about the likely achieved tidal volumes with non-invasive support like nCPAP or high flow cannulae, the use of electrical impedance has been investigated as a possible guide for therapy, but published studies have so far examined relatively small numbers of subjects. $^{4}$ 
Some very tiny premature babies paradoxically avoid RDS. Smallfor-dates premature babies are at less risk to develop RDS than their AGA counterparts, but at greater risk to develop BPD if they do have RDS. This likely depends on the etiology of the fetal growth restriction (FGR). Park et $\mathrm{al}^{5}$ examined the relationship between FGR in the absence of infection and inflammation with the risk to develop RDS, providing some mechanistic clues. Since there is an association of chorioamnionitis and post-natal infection with the risk for developing BPD, they excluded cases with inflammation/infection. They cultured amniotic fluid, measured an inflammatory marker (MMP-8) in amniotic fluid, and examined the histology of the umbilical cord and placenta. They found that FGR was relatively protective, confirming some earlier observations about SGA babies and risk to develop RDS.

Severe fetal growth restriction is one of the predisposing factors for pulmonary hypertension (PH). Pre-clinical studies have demonstrated that early life pulmonary insults can induce pulmonary hypoplasia and $\mathrm{PH}$. In an effort to identify patients that might be at particular risk to develop pulmonary hypertension, König et $\mathrm{al}^{6}$ correlated systemic markers associated with $\mathrm{PH}$ in term newbornsB-type natriuretic peptide (BNP) and N-terminal pro-BNP-with one measurement of $\mathrm{PH}$ in small premature babies. They chose the right ventricular systolic pressure determined by echocardiogram and found no significant relationship with the BNP moieties. The authors' rationale for their study was the desirability of a biomarker for $\mathrm{PH}$ since echocardiography availability is not universal. Differing mechanisms leading to impaired pulmonary vascular resistance may also be accompanied by differing host-responses to putative therapies. Bao et al, ${ }^{7}$ for example, show that babies and premature baboons that died with BPD may have had deficits in their ability to respond to inhaled nitric oxide, a widely used therapy for $\mathrm{PH}$, since they had defects in an amino acid transporter important for cellular uptake of S-nitrosocysteine, shown in some studies to be a chemical intermediate to inhaled NO effects. The approach in all forms of $\mathrm{PH}$ is inevitably complex and must include addressing multiple pathophysiologic mechanisms that contribute, including stabilization of the airways and ventilation, if therapies directed at pulmonary vascular smooth muscle are to be ultimately effective.

Since the respiratory system cellular maintenance and repair systems rely on a sufficiently numerous and well-positioned set of progenitor cells, it would be expected that disruption of this repertoire would have long term effects on the respiratory system development. For example, Spoel et al ${ }^{8}$ imaged adult congenital diaphragmatic hernia survivors using hyper-polarized ${ }^{3} \mathrm{H}$-MRI and demonstrated persistent micro-structural alveolar enlargement.

Kumar et al $^{9}$ demonstrated that severe oxidative stress $-85 \%$ $\mathrm{O}_{2} \times 12$ days -in postnatal mice altered respiratory system reactivity in adult mice, determined by in vivo methacholine challenge during whole body plethysmography. As expected, post-natal hyperoxia induced alveolar simplification. While some of the respiratory system sensitivity to inhaled methacholine may be attributable to loss of alveolar tethering of the airways, the authors showed that there was also increased methacholine sensitivity in isolated tracheal rings, suggesting intrinsic effects on airway smooth muscle. The authors observed durable effects on inflammation in the adult mice as well, showing persistent elevations of pulmonary leukotrienes. This study demonstrates changes in the alveolar and airway structure and function as well as a persistent change in the inflammatory environment. Such early life programming appears to be induced by nicotine as well, possibly through alterations of airway smooth muscle formation. Since perinatal nicotine exposure is associated with increased airway reactivity in offspring, Sakurai et $\mathrm{al}^{10}$ show that prenatal nicotine exposure in rats increases abundance of smooth muscle markers in postnatal rat lungs, but without accompanying markers that would point to epithelial-mesenchymal transformation. They concluded that the nicotine-induction of "myogenic" markers could explain the physiological phenotype. Corresponding evidence of airway hyperplasia in this model would link the authors' findings with their earlier reports of increased methacholine induced respiratory system resistance. ${ }^{11}$

The evidence for human susceptibility to neonatal and early childhood pulmonary insults that affect lung function in adulthood continues to mount, as reviewed by Goldizen et al. ${ }^{12}$ Impairments of small airway function were reported by Verheggen et $\mathrm{al}^{13}{ }^{13}$ reporting a case-control comparison of pulmonary function testing in 4- to 8-year old subjects born before 32 weeks with or without BPD. They used forced oscillometry or spirometry. They reported that pulmonary reactance, an oscillometric method used to assess small airway function, was worse in BPD subjects. Although this finding is not surprising, it should be tempered by the relatively low recruitment rate they experienced from their original qualifying cohort. Factors associated with BPD risk like duration of oxygen exposure and male sex were also associated with increased pulmonary reactance.

\section{3 | ASTHMA}

The genetic basis of asthma has been investigated in many studies recently. Hua et $\mathrm{al}^{14}$ investigated the gene-gene interactions among variants of the IL13, IL4, IL4RA, FCER1B, and ADRB2 genes, which have been associated with asthma in children, and demonstrated that single nucleotide polymorphisms IL13 rs20541, IL4 rs2243250, ADRB2 rs1042713n, and FCER1B rs569108 were associated with asthma. Moreover, risk of asthma was increased more than 10 times in carriers of all four risk homozygotes (IL13 rs20541 GG, IL4 rs2243250 TT, ADRB2 rs1042713 AA, and FCER1B rs569108 GG).

Genetic factors mediate many of the environmental influences on development of pediatric asthma. Joubert et $\mathrm{al}^{15}$ included 6685 newborns from 13 different cohorts in their analysis. They measured CpG-specific DNA methylation across the epigenome and identified about 3000 sites corresponding to differentially methylated genes. These results add to the evidence for a role for epigenetic mechanisms in the relationship between environmental smoke exposure during pregnancy and pediatric asthma. Gene-environment interaction is also important in the development of pediatric asthma. Research done in rural and urban parts of China on 854 children revealed that physician diagnosed asthma was significantly lower in children living in rural areas. Personal and family history of atopy, high consumption of milk products, and hospitalization younger than three years of age were significantly associated with asthma. Similarly, being a member of a 
crop-farming family and dust endoxtoxin levels were negatively associated with asthma in the child. ${ }^{16}$

Lautenbacher et $\mathrm{al}^{17}$ investigated the effects of vitamin D on pulmonary function and compared obese and non-obese asthmatic children. Although the frequency of vitamin $D$ deficiency was not different between groups, FEV1 and FRC were significantly worse in vitamin $\mathrm{D}$ deficient obese children than in normal-weight children. Moreover, TNF and IL-8 were higher in obese asthmatics, while the Th2 cytokine IL13 was higher in normal-weight asthmatics. However, these inflammatory measures were not related to the association of vitamin $D$ deficiency with poor lung function; thus implying an independent effect of vitamin $D$ deficiency.

Coexistence of obesity and poor asthma control is well known, but body mass index (BMI) may not reflect regional differences in adiposity. As part of the AsthMaP-2 Project that is an observational study of pediatric asthma, association of neck circumference and asthma control was assessed. ${ }^{18}$ It was demonstrated that, in boys, neck circumference combined with BMI explained the variability of asthma control test better than BMI alone.

Air pollution has a significant influence on respiratory health. Rice et $\mathrm{al}^{19}$ investigated the effect of traffic-related air pollution (TRAP) on the lung function development of 641 children. Living near a major roadway, and exposure to $\mathrm{PM}_{2.5}$ and black carbon were found to be associated with lower lung function in mid-childhood. Recent exposures were found to have more influence when compared to early life exposures. Similarly, Hasunumo et $\mathrm{al}^{20}$ estimated the influence of TRAP on the incidence and persistence of asthma between 18 months and 3 years of age. Their results demonstrated that TRAP was not related to incidence of asthma but increased the persistence of asthma that was already present at 18 months age. The effects of TRAP and proximity to major roads on pediatric respiratory health need to be considered when schools and areas of residence are being planned.

Modern living conditions include changing hygiene and exposure to air pollution, but also depression and stress. Alton et $\mathrm{al}^{21}$ investigated 791 women and their children at 3 years of age, to identify whether postpartum depression is a risk factor for preschool wheeze. Postpartum depression was present in about $8 \%$ of the women and it increased the risk of wheezing in girls but not boys. This finding is in concordance with the results of a recent systematic review reporting that maternal distress during pregnancy is associated with atopic diseases in children. ${ }^{22}$ Cano-Garcinuno et al ${ }^{23}$ analyzed data from more than 450 children and demonstrated that worse quality of life in parents was associated with an increase in the number of asthma exacerbations, unscheduled visits, and emergency visits due to asthma in children. These results reinforce that psychosocial and family factors need to be considered in evaluation and follow-up of asthma in children. Written asthma action plans are recommended for management of childhood asthma, but their use is not consistent. Simon et $\mathrm{al}^{24}$ investigated sociodemographic factors associated with increased risk of not receiving an asthma action plan, and reported that being a nonHispanic black, not having a private insurance, low family income, and living in non-core areas increased this risk.
Cysteinyl-leukotrienes may play an important role in exerciseinduced bronchoconstriction. In a prospective, open-label study, 21 children with suboptimally controlled asthma on low dose inhaled steroids, were enrolled to see if FEV1 response after single dose montelukast could predict effectiveness of long-term treatment. ${ }^{25}$ Addition of daily montelukast to inhaled corticosteroid treatment improved exercise-induced decrease in FEV1 in a significant proportion of cases. Moreover, change in FEV1 after single dose of montelukast was effective in predicting the response to long-term treatment.

The optimal dosing of albuterol in children remains uncertain. In a prospective, randomized, double blinded, controlled study, Muchao et $\mathrm{al}^{26}$ found no differences in length of stay in the emergency room, admission rate, need for additional treatments or Pediatric Respiratory Assessment Measure scores among dosing groups. Similarly, safety parameters did not differ between the two groups.

The search continues for useful biomarkers of inflammation in pediatric asthma management. Hamill et $\mathrm{al}^{27}$ investigated whether exhaled breath temperature, as a reflection of airway inflammation in asthma, is correlated with other asthma control measures. They demonstrated good repeatability of the test, but the results were not correlated with any other asthma control parameters such as asthma control test, exhaled nitric oxide or physicians' decision for treatment. Jochman et $\mathrm{al}^{28}$ obtained sputum inductions in young children and compared results from induced sputum with bronchoalveolar lavage fluid and blood. Less than half of the induced sputum samples were adequate for cytology and these had significantly lower number of eosinophils compared to blood and bronchoalveolar lavage fluid. Thus, they concluded that induced sputum is not reliable for assessing lower airway eosinophilic inflammation in preschool children. In a longitudinal observation study of 96 children aged 6-18 years, asthma control assessed by the asthma control test (ACT) was compared with exhaled breath nitric oxide (NO) and volatile organic compounds (VOC); there was no association between these exhaled markers and ACT, though a subset of exhaled VOC were identified that could categorize children with controlled versus uncontrolled asthma. ${ }^{29}$ Thomas et al ${ }^{30}$ showed that agreement between metacholine challenge test results, exhaled nitric oxide, and quality of life was poor in children with asthma, emphasizing that these parameters show different aspects of the disease and only a composite evaluation using all these tools can give us the big picture.

This year, the Childhood Asthma Management Program (CAMP) cohort published their longitudinal follow up results on FEV1 growth and decline in children with persistent asthma. ${ }^{31}$ Study subjects were followed from ages 5-12 years until the third decade of life, with annual spirometry. They demonstrated that nearly $75 \%$ of these subjects with childhood asthma had abnormal growth and/or early decline of lung function as adults. Prenatal maternal smoke exposure, male gender, reduced lung function at the beginning of study, and increased airway hyperreactivity were associated with adult lung function abnormalities. These results add to the growing body of data linking childhood respiratory disease to longer term health issues. 


\section{4 | PHYSIOLOGY AND LUNG FUNCTION TESTING}

Normal reference data are critical for interpreting the results of pulmonary physiologic measurements. It is well known that spirometric values differ by race and sex. ${ }^{32,33}$ However, there are limited data on racial differences in the diffusion capacity of the lung to carbon monoxide (DLCO). Kim et al ${ }^{34}$ obtained DLCO and alveolar volume (Va) measurements in 151 healthy African-American (AA) children ages 5-18 years and 301 Caucasian (C) children of the same age. They found that AA children have lower DLCO and Va compared to $C$ children for the same height, gender, and age. Although respiratory disease is the leading cause of morbidity and mortality in the Hopi Nation, there are no spirometry reference data available for this population. Arnall et al ${ }^{35}$ performed spirometry in 292 health Hopi children ages 4-13 years; results from Hopi children differed significantly from other racial and ethnic groups, specifically Navajo, Caucasian, Mexican-American, African-American. The availability of specific reference data from these two studies will improve the ability to provide clinical care and conduct research in these populations.

Sickle cell disease (SCD) is associated with respiratory complications including obstructive lung disease, acute chest syndrome (ACS), and obstructive sleep apnea. ${ }^{36}$ Despite the impact of respiratory disease on SCD outcomes, there remains limited data regarding the prevalence of respiratory abnormalities in SCD patients and their changes over time. SCD patients with asthma have poorer outcomes, but it is unknown if airway hyperresponsiveness (AHR) itself can be present in SCD without asthma. Shilo et $\mathrm{al}^{37}$ determined the prevalence of AHR in SCD patients without asthma or a recent history of ACS using methacholine challenge testing. They found that $72 \%$ off children had AHR and $31 \%$ reported asthma-like symptoms despite not having the diagnosis of asthma. Although inflammatory markers did not correlate with AHR, the degree of AHR was less in those study subjects who were receiving hyroxyurea. Their results demonstrate that there is a high prevalence of AHR in SCD patients and hydroxyurea may be helpful in decreasing AHR in SCD. Lunt et $\mathrm{al}^{38}$ prospectively assessed longitudinal lung function in children with SCD. They analyzed data from two cohorts. The first cohort consisted of 47 SCD subjects and 26 controls with a median age of 8.8 years and follow up of 2 years, while the second cohort had 45 SCD subjects and 26 controls with a median age of 10.2 years and follow up of 10 years. In both cohorts, lung function declined significantly in SCD patients compared to controls, but the rate of decline was greater in the younger cohort, suggesting that the most rapid loss of lung function occurs in early childhood. Obstructive defects were more common at baseline, but over time the prevalence of restrictive defects increased. A history of ACS was associated with more rapid decline in lung function. The results of this study highlight the impact of SCD on lung function and suggest that interventions in early childhood to reduce ACS risk may help preserve lung function in these patients.

Impulse oscillometry (IOS) uses the forced oscillation technique to assess airway function and does not require the maximal forced expiratory maneuver needed for spirometry. ${ }^{39}$ IOS measures total respiratory impedance $(Z)$ which is a complex number that incorporates both the in and out phase elements of resistance; the former is resistance $(R)$, and the latter is termed the reactance $(X)$. R reflects the airway resistive properties of the respiratory system, while $X$ reflects the visco-elastic and inertive elements of the respiratory system. Gochicoa-Rangel ${ }^{40}$ used $\mathrm{FO}$ to assess respiratory function in 31 patients with Duchenne muscular dystrophy (DMD), who may not have enough muscle strength to perform spirometry. Compared to age and anthropomorphic matched healthy controls, patients with DMD demonstrated higher $\mathrm{R}$ and lower $\mathrm{X}$. $\mathrm{R}$ and $\mathrm{X}$ were abnormal in $\mathrm{DMD}$ patients with less severe disease and tended to normalize with more severe disease. The authors speculate that dystrophin, which is expressed in the airway smooth muscle (ASM) of DMD patients, may induce pseudohypertrophy similar to that seen in the skeletal muscle of these patients. This in turn would reduce airway caliber and increase R. Similarly, ASM pseudohypertrophy would affect the visco-elastic properties of the lung, lowering $X$. This study demonstrates that IOS can be a useful technique to identify respiratory function abnormalities in DMD patients who cannot perform spirometry. Sakarya et al ${ }^{41}$ obtained IOS data in a cohort of 49 children ages 3-18 years (mean age 7.75 years) with CF during a clinically stable period, at the onset of a pulmonary exacerbation, and after treatment for the exacerbation. At baseline, CF patients had elevated $\mathrm{R}$ and $\mathrm{X}$ compared to healthy control children. With an exacerbation, $\mathrm{R}$ increased and $\mathrm{X}$ decreased; both measures improved after treatment of the exacerbation. Although other studies have demonstrated abnormal baseline IOS measurements in CF children and improvement after exacerbation treatment, ${ }^{42,43}$ this study is the first to prospectively track IOS changes at baseline and during an exacerbation. Their results suggest that IOS may be a useful method to obtain objective measures of lung function in children with CF at baseline and during illnesses.

Pulmonary physiologic measurements in infants are a challenge because they cannot perform cooperative respiratory maneuvers such as forced expiration, and their rapid respiratory rates and small tidal volumes make precise measurement of pressure, flow, and gas composition difficult. Shawcross et $\mathrm{al}^{44}$ reported a novel method to measure lung volumes using multiple breath washout (MBW). By collecting the expired gas and analyzing it after the washout is completed, they avoided the need for simultaneous flow measurement and integration of flow and gas composition signals utilized in current commercial MBW devices. They tested their method in an infant lung model and showed it to be highly accurate in measuring functional residual capacity. Their method has the added advantage of not using a pneumotachometer (PNT), which reduces the dead space in the circuit. Potential limitations of this method include a limit on the size of the patients studied due to limitations on the volume of the washout collection bag and an inability of detect leak since there is no PNT. This system will require further study in human subjects before determining its utility in clinical research and patient care.

Tidal breathing analysis is a method to assess respiratory function that does not require sedation or manipulation of the infant's respiratory system. ${ }^{45}$ Respiratory inductance plethysmography has been used to obtain tidal breathing data, but it only measures chest and abdominal excursion at two points, which does not accurately reflect the true mechanics of the respiratory system. Reinaux et al ${ }^{46}$ used opto-electronic plethysmography (OEP) to measure motion at 52 
sites placed in the thorax and abdomen of healthy infants and compared the results obtained using this system to those obtained using a mask with PNT. They found that measurement of tidal volume using OEP was in good agreement with that obtained using a PNT with a mean difference of only $0.02 \mathrm{~mL}$. The ability to obtain tidal breathing measurements may lead to new insights into changes in chest and abdominal motion in pediatric respiratory disease.

Bronchopulmonary dysplasia (BPD) is the most common respiratory complication of preterm birth. Despite advances in neonatal medicine, BPD still occurs in $30-50 \%$ of infants born before a gestational age (GA) of 29 weeks. ${ }^{47}$ Lung function measured in infants with a history of BPD is lower than that of infants without this complication, but little is known about changes in lung function in infants with BPD compared to those without BPD. Sanchez-Solis et $\mathrm{al}^{48}$ performed infant lung function testing using the raised volume rapid thoracoabdominal compression technique in 71 preterm infants, 32 of which had BPD, at 6 months and 12 months corrected GA. Although forced vital capacity (FVC) was similar in both groups, all other forced expiratory flow measures were lower in the BPD infants. A similar pattern persisted at the follow up test, indicating a lack of catch-up lung function in BPD infants. BPD infants also had significantly lower weight and length z-scores compared to nonBPD infants, and a higher length growth velocity between the two tests was associated with better improvements in forced expiratory flows. Fortuna et $\mathrm{al}^{49}$ obtained longitudinal lung function data at 8 and 12 years in 48 children born at $<29$ weeks GA; 28 of these children had BPD. Similar to the findings in infants, FVC was not significantly different between the BPD and non-BPD children, but all preterm children had lower forced expiratory flows compared to health controls, with the BPD children having even lower flows compared to non-BPD children. Over the 4 year follow up period, the z-scores on all spirometric measures in healthy control and non-BPD preterm children remained stable. However, in children with a history of BPD, the forced expiratory volume in $1 \mathrm{~s} z$-score decreased significantly, as did other measures of expiratory flow. Taken together, these studies demonstrate that preterm infants with BPD have greater airflow obstruction than non-BPD infants and that over time, not only does catch-up lung function not occur, but these deficits become even greater. Better growth is associated with better improvement in lung function, emphasizing the importance of focusing on and optimizing nutrition in early life for BPD infants.

\section{5 | RESPIRATORY INFECTIONS}

Lower respiratory infection is the single most common cause of childhood mortality worldwide, particularly among young children and children in sub-Saharan Africa and Asia. ${ }^{50}$ Multiple articles were published in Pediatric Pulmonology in 2016 relevant to various aspects of respiratory infection, with a substantial number on viral bronchiolitis.

Acute viral bronchiolitis, due to RSV and other pathogens, continues to have a major impact worldwide on childhood mortality and hospital admissions, ${ }^{51}$ is associated with subsequent asthma and allergy risk, ${ }^{52}$ and could be increasing in incidence. ${ }^{53}$ Cangiano et $a^{54}$ noted a higher incidence of acute bronchiolitis every 4 years among previously health term infants, largely due to RSV; rhinovirus was a less common cause and had less tendency to occur in seasonal clusters than RSV. While a commonly used standard definition for bronchiolitis is initial episode of wheezing in a child $<12$ months old, variability in how clinicians actually define bronchiolitis was highlighted in a report from Fernandes et al. ${ }^{55}$ Beamer et $\mathrm{al}^{56}$ carried out an interesting risk factor analysis in the context of the Tucson Children's Respiratory Health Study. Spatial clustering analysis, based upon each participant's birth address, was performed for four LRI phenotypes. Being in a viral cluster was associated with poorer housing conditions $(O R=1.28$, $P=0.01$ ), while being in a RSV cluster was associated with increased air pollution $(\mathrm{OR}=1.14, P=0.006)$, poorer housing conditions $(\mathrm{OR}=1.54$, $P=0.003)$, and higher SES (OR $=0.77, P=0.001)$.

Treatment for acute bronchiolitis remains largely supportive and progress has been made in reducing widespread use of corticosteroids and bronchodilators, which have previously been shown to be ineffective. ${ }^{57}$ Flores et al $^{58}$ conducted a randomized clinical trial comparing $3 \%$ hypertonic saline to normal saline in previously healthy infants hospitalized with mild-to-moderate acute viral bronchiolitis. The median length of hospital stay, severity score, and need for supplemental oxygen did not differ significantly between groups. Patients receiving hypertonic saline had significantly more cough $(46 \%$ vs $20 \%, P=0.025)$. Thus, the study does not support the use of nebulized hypertonic saline over normal saline in therapy of hospitalized children with mild-to-moderate acute viral bronchiolitis. In another study with practical implications, Heikkila et $\mathrm{al}^{59}$ analyzed cost of care for infants hospitalized with bronchiolitis and found that use of high-flow nasal cannula (HFNC) for oxygen delivery was associated with lower cost, largely through reductions in PICU admission.

Viral etiologies for community acquired pneumonia (CAP) in children were investigated in a large prospective study comparing children with CAP to asymptomatic controls. ${ }^{60}$ Analysis of attributable fraction suggested that influenza, RVS, and human metapneumovirus are more common among CAP than in controls, but that parainfluenza, coronavirus, rhinovirus, and adenovirus were not. Ambroggio et al ${ }^{61}$ investigated antibiotic treatment in a large retrospective cohort study of children with CAP during outpatient management in the Geisinger Health System. The primary exposure was receipt of beta-lactam monotherapy or beta-lactam/macrolide combination therapy. Children 6-18 years of age who received combination therapy were less likely to fail treatment than those who received beta-lactam monotherapy (propensity-adjusted odds ratio, 0.51; 95\% confidence interval, 0.28, 0.95).

Effects of air pollution on respiratory infections in children were reviewed in a state of the art article by Goldizen et al, ${ }^{12}$ who summarized current evidence for significant impacts of particulate matter, $\mathrm{NO}_{2}$, traffic-related air pollution, and biomass fuel exposures on risk for respiratory infection. Van Rie et al ${ }^{62}$ investigated the frequency of immune reconstitution inflammatory syndrome (IRIS) in HIV-positive South African children who initiated combination antiretroviral therapy (CART) while on TB treatment. In 7 of the 104 children enrolled in the cohort, symptoms and/or clinical or 
radiological signs suggestive of paradoxical TB-IRIS developed after a median of 14 days of cART. Chang et al, ${ }^{63}$ in a state of the art review, summarized our current knowledge about protracted bacterial bronchitis (PBB), emphasizing the role of Hemophilus influenzae as an etiology, and positing that PBB may exist on a continuum of persistent infection, in some cases leading to bronchiectasis, which was updated by the same group of authors in a separate state of the art review. ${ }^{64}$ Coccidioidomycosis is unusual in young children but Lee et $\mathrm{al}^{65}$ reported a case series of 13 infants in the Sam Joaquin Valley of California. The majority presented with fever and cough, and required prolonged hospitalization; all patients had pulmonary infiltrates including those without respiratory symptoms, and some had disseminated disease. In the right environmental context, genetic factors may predispose to lower respiratory infection. Sheen et al ${ }^{66}$ reported an association between low vitamin D levels in cord blood, a genetic variant at the 17q12-21 locus, and risk for lower respiratory infection in the Cohort for Childhood Origin of Asthma and allergic diseases (COCOA) birth cohort.

\section{REFERENCES}

1. Gerdes JS, Sivieri EM, Abbasi S. Factors influencing delivered mean airway pressure during nasal CPAP with the RAM cannula. Pediatr Pulmonol. 2016;51:60-69.

2. Kugelman A, Bromiker R, Riskin A, et al. Diagnostic accuracy of capnography during high-frequency ventilation in neonatal intensive care units. Pediatr Pulmonol. 2016;51:510-516.

3. Van der Burg PS, de Jongh FH, Miedema M, Frerichs I, van Kaam AH. The effect of prolonged lateral positioning during routine care on regional lung volume changes in preterm infants. Pediatr Pulmonol. 2016;51:280-285

4. Durlak W, Kwinta P. Role of electrical impedance tomography in clinical practice in pediatric respiratory medicine. ISRN Pediatrics 2013;529038. https://doi.org/10.1155/2013/529038

5. Park C-W, Park JS, Jun JK, Yoon BH. FGR in the setting of preterm sterile intra-uterine milieu is associated with a decrease in RDS. Pediatr Pulmonol. 2016;51:812-819.

6. König K, Guy KJ, Walsh G, Drew SM, Barfield CP. Association of BNP, NTproBNP, and early postnatal pulmonary hypertension in very preterm infants. Pediatr Pulmonol. 2016;51:820-824.

7. Bao EL, Chystsiakova A, Brahmajothi MV, et al. Bronchopulmonary dysplasia impairs L-type amino acid transporter-1 expression in human and baboon lung. Pediatr Pulmonol. 2016;51:1048-1056.

8. Spoel M, Marshall $\mathrm{H}$, IJsselstijn $\mathrm{H}$, et al. Pulmonary ventilation and micro-structural findings in congenital diaphragmatic hernia. Pediatr Pulmonol. 2016;51:517-524.

9. Kumar VHS, Lakshminrusimha S, Kishkurno S, et al. Neonatal hyperoxia increases airway reactivity and inflammation in adult mice. Pediatr Pulmonol. 2016;51:1131-1141.

10. Sakurai R, Liu J, Gong M, Bo J, Rehan VK. Perinatal nicotine exposure induces myogenic differentiation, but not epithelial-mesenchymal transition in rat offspring lung. Pediatr Pulmonol. 2016;51:1142-1150.

11. Rehan VK, Liu J, Naeem E, et al. Perinatal nicotine exposure induces asthma in second generation offspring. BMC Med. 2012;10:129.

12. Goldizen FC, Sly PD, Knibbs LD. Respiratory effects of air pollution on children. Pediatr Pulmonol. 2016;51:94-108.

13. Verheggen M, Wilson AC, Pillow JJ, Stick SM, Hall GL. Respiratory function and symptoms in young preterm children in the contemporary era. Pediatr Pulmonol. 2016;51:1347-1355.
14. Hua L, Zuo XB, Bao YX, et al. Four-locus gene interaction between IL13, IL4, FCER1B, and ADRB2 for asthma in Chinese Han children. Pediatr Pulmonol. 2016;51:364-371.

15. Joubert BR, Felix JF, Yousefi P, et al. DNA methylation in newborns and maternal smoking in pregnancy: genome-wide consortium metaanalysis. Am J Hum Genet. 2016;98:680-696.

16. Feng $M$, Yang Z, Pan L, et al. Associations of early life exposures and environmental factors with asthma among children in rural and urban areas of Guangdong, China. Chest. 2016;149:1030-1041.

17. Lautenbacher LA, Jariwala SP, Markowitz ME, Rastogi D. Vitamin D and pulmonary function in obese asthmatic children. Pediatr Pulmonol. 2016;51:1276-1283.

18. Maltz L, Matz EL, Gordish-Dressman H, et al. Sex differences in the association between neck circumference and asthma. Pediatr Pulmonol. 2016;51:893-900.

19. Rice MB, Rifas-Shiman SL, Litonjua AA, et al. Lifetime exposure to ambient pollution and lung function in children. Am J Respir Crit Care Med. 2016;193:881-888.

20. Hasunuma H, Sato T, Iwata $\mathrm{T}$, et al. Association between trafficrelated air pollution and asthma in preschool children in a national Japanese nested case-control study. BMJ Open. 2016;6:e010410.

21. Alton ME, Zeng Y, Tough SC, Mandhane PJ, Kozyrskyj AL. Postpartum depression, a direct and mediating risk factor for preschool wheeze in girls. Pediatr Pulmonol. 2016;51:349-357.

22. Andersson NW, Hansen MV, Larsen AD, Hougaard KS, Kolstad HA, Schlünssen V. Prenatal maternal stress and atopic diseases in the child: a systematic review of observational human studies. Allergy. 2016;71:15-26.

23. Cano-Garcinuño A, Mora-Gandarillas I, Bercedo-Sanz A, et al. Looking beyond patients: can parents' quality of life predict asthma control in children? Pediatr Pulmonol. 2016;51:670-677.

24. Simon AE, Akinbami LJ. Asthma action plan receipt among children with asthma 2-17 years of age, United States, 2002-2013. J Pediatr. 2016;171:283-289.

25. Kersten ET, Akkerman-Nijland AM, Driessen JM, Diamant Z, Thio BJ. Can a single dose response predict the effect of montelukast on exerciseinduced bronchoconstriction? Pediatr Pulmonol. 2016;51:470-477.

26. Muchão FP, Souza JM, Torres HC, et al. Albuterol via metered-dose inhaler in children: lower doses are effective, and higher doses are safe. Pediatr Pulmonol. 2016;51:1122-1130.

27. Hamill L, Ferris K, Kapande K, et al. Exhaled breath temperature measurement and asthma control in children prescribed inhaled corticosteroids: a cross sectional study. Pediatr Pulmonol. 2016; 51:13-21.

28. Jochmann A, Artusio L, Robson K, et al. Infection and inflammation in induced sputum from preschool children with chronic airways diseases. Pediatr Pulmonol. 2016;51:778-786.

29. Van Vliet D, Smolinska A, Jöbsis Q, et al. Association between exhaled inflammatory markers and asthma control in children. J Breath Res. 2016;10:016014.

30. Thomas B, Chay OM, Allen JC, Jr, et al. Concordance between bronchial hyperresponsiveness, fractional exhaled nitric oxide, and asthma control in children. Pediatr Pulmonol. 2016;51:1004-1009.

31. McGeachie MJ, Yates KP, Zhou X, et al. Patterns of growth and decline in lung function in persistent childhood asthma. $N$ Engl J Med. 2016;374:1842-1852

32. Oscherwitz M, Edlavitch SA, Baker TR, Jarboe T. Differences in pulmonary functions in various racial groups. Am J Epidemiol. 1972; 96:319-327.

33. Quanjer PH, Stanojevic S, Cole TJ, et al. Multi-ethnic reference values for spirometry for the 3-95-yr age range: the global lung function 2012 equations. Eur Respir J. 2012;40:1324-1343. 
34. Kim Y-J, Christoph K, Yu Z, Eigen H, Tepper RS. Pulmonary diffusing capacity in healthy African-American and Caucasian children. Pediatr Pulmonol. 2016;51:84-88.

35. Arnall DA, Nelson AG, Hearon CM, Interpreter C, Kanuho V. Spirometric reference values for Hopi Native American children ages 4-13 years. Pediatr Pulmonol. 2016;51:386-393.

36. Gladwin MT, Vichinsky E. Pulmonary complications of sickle cell disease. New Engl J Med. 2008;359:2254-2265.

37. Shilo NR, Alawadi A, Allard-Coutu A, et al. Airway hyperreactivity is frequent in non-asthmatic children with sickle cell disease. Pediatr Pulmonol. 2016;51:950-957.

38. Lunt $A, M c G h e e ~ E$, Sylvester $K$, et al. Longitudinal assessment of lung function in children with sickle cell disease. Pediatr Pulmonol. 2016; 51:717-723.

39. Goldman MD. Clinical application of forced oscillation. Pulm Pharmacol \& Ther. 2001;14:341-350.

40. Gochicoa-Rangel L, Vargas MH, Alonso-Gómez JL, et al. Respiratory impedance in patients with Duchenne muscular dystrophy. Pediatr Pulmonol. 2016;51:1072-1079.

41. Sakarya A, Uyan ZS, Baydemir C, et al. Evaluation of children with cystic fibrosis by impulse oscillometry when stable and at exacerbation. Pediatr Pulmonol. 2016;51:1151-1158.

42. Gangell CL, Horak F, Jr., Patterson HJ, Sly PD, Stick SM, Hall GL. Respiratory impedance in children with cystic fibrosis using forced oscillations in clinic. Eur Respir J. 2007;30:892-897.

43. Ren CL, Brucker JL, Rovitelli AK, Bordeaux KA. Changes in lung function measured by spirometry and the forced oscillation technique in cystic fibrosis patients undergoing treatment for respiratory tract exacerbation. Pediatr Pulmonol. 2006:41:345-349.

44. Shawcross A, Murray CS, Goddard N, Gupta R, Watson S, Horsley A. Accurate lung volume measurements in vitro using a novel inert gas washout method suitable for infants. Pediatr Pulmonol. 2016;51: 491-497.

45. Palmer J, Allen J, Mayer O. Tidal breathing analysis. NeoReviews. 2004;5:e186-e193.

46. Reinaux CM, Aliverti A, da Silva LG, et al. Tidal volume measurements in infants: opto-electronic plethysmography versus pneumotachograph. Pediatr Pulmonol. 2016;51:850-857.

47. Poindexter BB, Feng R, Schmidt B, et al. Prematurity and respiratory outcomes program. comparisons and limitations of current definitions of bronchopulmonary dysplasia for the prematurity and respiratory outcomes program. Ann Am Thorac Soc. 2015;12: 1822-1830.

48. Sanchez-Solis M, Perez-Fernandez V, Bosch-Gimenez V, Quesada JJ, Garcia-Marcos L. Lung function gain in preterm infants with and without bronchopulmonary dysplasia. Pediatr Pulmonol. 2016;51: 936-942.

49. Fortuna M, Carraro S, Temporin E, et al. Mid-childhood lung function in a cohort of children with "new bronchopulmonary dysplasia". Pediatr Pulmonol. 2016;51:1057-1064.

50. Global Burden of Disease Pediatrics Collaboration, Kyu HH, Pinho C, et al. Global and national burden of diseases and injuries among children and adolescents between 1990 and 2013: findings from the Global Burden of Disease 2013 Study. JAMA Pediatr. 2016;170: 267-287

51. Meissner HC. Viral bronchiolitis in children. New Engl J Med. 2016; $374: 62-72$
52. Lu S, Hartert TV, Everard ML, et al. Predictors of asthma following severe respiratory syncytial virus (RSV) bronchiolitis in early childhood. Pediatr Pulmonol. 2016;51:1382-1392.

53. Green CA, Yeates D, Goldacre A, et al. Admission to hospital for bronchiolitis in England: trends over five decades, geographical variation and association with perinatal characteristics and subsequent asthma. Arch Dis Child. 2016;101:140-146.

54. Cangiano G, Nenna R, Frassanito A, et al. Bronchiolitis: analysis of 10 consecutive epidemic seasons. Pediatr Pulmonol. 2016;51: 1330-1335.

55. Fernandes RM, Andrade MG, Constant C, et al. Acute viral bronchiolitis: physician perspectives on definition and clinically important outcomes. Pediatr Pulmonol. 2016;51:724-732.

56. Beamer PI, Lothrop N, Lu Z, et al. Spatial clusters of child lower respiratory illnesses associated with community-level risk factors. Pediatr Pulmonol. 2016;51:633-642.

57. Ralston SL, Garber MD, Rice-Conboy E, et al. Value in inpatient pediatrics network quality collaborative for improving hospital compliance with AAP bronchiolitis guideline (BQIP). A multicenter collaborative to reduce unnecessary care in inpatient bronchiolitis. Pediatrics. 2016;137:e20150851.

58. Flores $\mathrm{P}$, Mendes AL, Neto AS. A randomized trial of nebulized $3 \%$ hypertonic saline with salbutamol in the treatment of acute bronchiolitis in hospitalized infants. Pediatr Pulmonol. 2016;51: 418-425.

59. Heikkilä P, Forma L, Korppi M. High-flow oxygen therapy is more costeffective for bronchiolitis than standard treatment-a decision-tree analysis. Pediatr Pulmonol. 2016;51:1393-1402.

60. Self WH, Williams DJ, Zhu Y, et al. Respiratory viral detection in children and adults: comparing asymptomatic controls and patients with community-acquired pneumonia. J Infect Dis. 2016;213:584-591.

61. Ambroggio L, Test M, Metlay JP, et al. Beta-lactam versus betalactam/macrolide therapy in pediatric outpatient pneumonia. Pediatr Pulmonol. 2016;51:541-548.

62. Van Rie A, Sawry S, Link-Gelles R, et al. Paradoxical tuberculosisassociated immune reconstitution inflammatory syndrome in children. Pediatr Pulmonol. 2016:51:157-164.

63. Chang $A B$, Upham JW, Masters IB, et al. Protracted bacterial bronchitis: the last decade and the road ahead. Pediatr Pulmonol. 2016;51:225-242.

64. Goyal V, Grimwood K, Marchant J, Masters IB, Chang AB. Pediatric bronchiectasis: no longer an orphan disease. Pediatr Pulmonol. 2016;51:450-469.

65. Lee JM, Graciano AL, Dabrowski L, Kuzmic B, Tablizo MA. Coccidioidomycosis in infants: a retrospective case series. Pediatr Pulmonol. 2016;51:858-862.

66. Sheen $\mathrm{YH}$, Lee $\mathrm{E}$, Kang $\mathrm{MJ}$, et al. Interaction between 25hydroxyvitamin $D$ and variants at $17 q 12-21$ on respiratory infections. Pediatr Pulmonol. 2016;51:958-967.

How to cite this article: Auten R, Ren C, Yilmaz O, Noah TL. Pediatric pulmonology year in review 2016: Part 2. Pediatric Pulmonology. 2017;52:1219-1225. https://doi.org/10.1002/ppul.23719 